\title{
EL DERECHO A LA EDUCACIÓN Y LA RESOCIALIZACIÓN DE LOS INTERNOS EN UN ESTABLECIMIENTO PENITENCIARIO.
}

\section{THE RIGHT TO EDUCATION AND THE RESOCIALIZATION OF INMATES IN THE PENITENTIARY INSTITUTION}

\author{
Gina Pamela Tapia Liendo ${ }^{1}$ \\ https://orcid.org/0000-0002-7376-295X \\ giptapia@virtual.upt.pe \\ Gonzalo Fernan Zegarra Ramirez ${ }^{1}$ \\ https://orcid.org/0000-0003-4899-3438 \\ gzegarraramirez@gmail.com
}

\begin{abstract}
RESUMEN
Se realiza un estudio con el fin de analizar en qué medida se garantiza el derecho a la educación en la resocialización de los internos en el establecimiento penitenciario Pocollay de Tacna, 2019. La investigación es de tipo básica, diseño no experimental, transversal, de nivel descriptiva, cuyo método lógico inductivo, permite el razonamiento partiendo de casos particulares, a conocimientos generales. Para el levantamiento de la información se aplicó el cuestionario, la entrevista y la ficha de análisis como instrumentos de medición; los cuales permitieron recoger información, y medir las variables de estudio. La muestra estuvo conformada por 88 internos y un directivo del Centro Penitenciario Pocollay de Tacna. Los resultados obtenidos permitieron establecer que: El derecho a la educación se garantiza en mínima medida en la resocialización de los internos en el establecimiento penitenciario Pocollay de Tacna, 2019.
\end{abstract}

Palabras Clave: Derecho, educación, resocialización, internos, reeducación, rehabilitación, reincorporación

\begin{abstract}
A study is carried out in order to analyze to what extent the right to education is guaranteed in the resocialization of inmates in the Pocollay de Tacna penitentiary establishment, 2019. The research is of basic type, non-experimental design, transversal, descriptive level, whose logical inductive method, allows reasoning starting from particular cases, to general knowledge. For the collection of information, the questionnaire, the interview and the analysis sheet were used as measurement instruments; which allowed collecting information and measuring the study variables. The sample consisted of 88 inmates and a manager of the Pocollay Penitentiary Center in Tacna. The results obtained made it possible to establish that: The right to education is guaranteed to a minimal extent in the resocialization of inmates in the Pocollay Penitentiary Establishment of Tacna, 2019.
\end{abstract}

Keywords: Law, education, resocialization, interns, reeducation, rehabilitation, reinstatement.

\footnotetext{
1 Universidad Privada de Tacna. Facultad de Derecho y Ciencias Políticas.
} 


\section{INTRODUCCIÓN}

"La educación es un derecho que hace a la condición del ser humano, ya que a partir de ella se construye el lazo de pertenencia a la sociedad, a la palabra, a la tradición, al lenguaje, en definitiva, a la transmisión y recreación de la cultura, esencial para la condición humana" (Núñez, 2010, pág. 157). Así, quien no obtiene o haga uso de este derecho perderá la oportunidad de pertenecer a la sociedad, participar y convertirse en ciudadano de manera real, y los ciudadanos hacen uso de sus derechos y cumplen con sus deberes para promover el desarrollo de la sociedad. En materia de educación, no solo se debe hacer uso del derecho por sí solo, sino que el Estado debe garantizar plenamente el derecho y considerar lineamientos y políticas para la sociedad. En el Perú vivimos en una democracia formal, pero la situación de ejercicio autoritario del poder sigue existiendo; corrupción, impunidad, restricciones al acceso a la justicia, y participación política en diversos sectores de la población, la desigualdad en la distribución de la riqueza va en aumento. Además del ejercicio de los derechos económicos, sociales y culturales (laborales, de seguridad, sociales, sanitarios, educativos, etc.), estas características harán que muchos grupos sociales queden más excluidos económica, social y políticamente.

"La vulnerabilidad social que padecen estos grupos, los constituye como seres proclives a la exclusión, la marginalidad, la violencia, la desocupación y otras tantas penurias (...) La cárcel es el lugar en el cual terminan aquellas personas que, en su mayoría, no han tenido educación, trabajo, salud y ningún tipo de garantías"(Scarfó, 2002). En general, especialmente en las cárceles, esto es una garantía de las condiciones humanitarias de quienes han cometido delitos. El encarcelamiento, incluso si es un castigo razonable, no debe privar aún más a la persona de los derechos civiles y los derechos humanos inherentes; las prisiones se utilizan principalmente como "soluciones" para resolver conflictos sociales $y$, entre otras cosas, también constituyen hombres y mujeres. "Depósitos punitivos". Además, se ha comprobado que, en todo momento histórico, la restricción se dirige a un determinado tema social. Por tanto, las cárceles son lugares donde la mayoría de las personas no tienen pleno acceso a la educación, el trabajo, la salud, la vivienda y otro tipo de garantías y derechos. El sistema los genera y los elimina, como una gran máquina de vapor. Cada vez que el Estado ha tenido que reaccionar frente a hechos o delitos que han puesto en peligro la seguridad ciudadana sólo ha recurrido a aumentar las penas privativas de libertad o incrementar el resguardo policial en las zonas consideradas de mayor riesgo.

Miles de personas fueron detenidas y condenadas en las cárceles peruanas. En el Centro Penitenciario Pocollay de Tacna podemos considerar los imputados y condenados en prisión, incluidos los analfabetos, los presos de primaria y secundaria incompletos, los presos de educación superior no universitaria incompleta y los estudios universitarios. En el marco de la política penitenciaria nacional, la educación penitenciaria se considera uno de los elementos básicos para el tratamiento de los reclusos. Las actividades educativas realizadas en las organizaciones penitenciarias estatales ayudarán a la resocialización de las cárceles. La educación es un derecho humano fundamental, esencial para poder ejercitar todos los demás derechos y que tiene como fin el desarrollo integral del sujeto. Que una persona acceda a la educación implica entonces que pueda crear un lazo de pertenencia a la sociedad y, en pocas palabras, a la transmisión y recreación de la cultura. Es el Estado quien debe garantizar y promover el goce efectivo de éste y de los que derivan de éste, ya que en teoría la persona encarcelada sólo está privada de su libertad ambulatoria. Cabe señalar que el desarrollo de este derecho en el ámbito carcelario (no solo considerado un medio de encarcelamiento, sino también un medio de castigo, disciplina, aislamiento, control, etc.) se cruza con la complejidad del proceso social.

El Comité de Derechos Económicos, Sociales y Culturales celebró una reunión sobre el artículo 13 del Pacto Internacional de Derechos Económicos, Sociales y Culturales; el derecho a la educación debe entenderse como: su forma y en todos los niveles debe tener ciertas relaciones mutuas Las características básicas de la asociación (asequibilidad, accesibilidad, aceptabilidad, adaptabilidad). En este sentido, esta pregunta surgió para comprobar si la educación que se realiza en el penal de hombres de Pocollay satisface estas características educativas, y plantea la pregunta actual: "El 
establecimiento educativo establecido por el Penal en Tacna Derechos y restitución, 2019. ¿En qué medida se garantiza el derecho a la educación en la resocialización de los internos en el establecimiento penitenciario Pocollay de Tacna, 2019? la problemática penitenciaria se manifiesta en los bajos niveles de capacitación, debido a los incipientes programas educativos que se desarrollan al interior de los penales, ello sumado a las inadecuadas condiciones para poder efectivizar este derecho; ello no garantiza el derecho a la educación en los internos. Consiguientemente el presente trabajo de investigación tiene una trascendencia teórica, práctica y social.

La trascendencia teórica de este trabajo se centra ampliamente en la teoría del derecho a la educación y la resocialización de los presos. Y a través del derecho comparado, es posible analizar las diferentes normas que deben protegerse para proteger el derecho a la educación de la prisión. En cuanto a la relevancia jurídica, este trabajo ayudará a los juristas a comprender más profundamente el tema, impulsando así medidas legislativas para garantizar el derecho a la educación y asegurar que los presos puedan reintegrarse a la sociedad. En cuanto a la trascendencia social, los beneficiarios inmediatos serán la población penitenciaria y la sociedad en su conjunto, y utilizarán el método de plan de acción y el sistema de oportunidades para el personal penitenciario. En el contexto de las penas privativas de libertad, el derecho de los condenados a acceder a una educación al interior de los Centros Penitenciarios resulta en extremo difícil cuando ni la normativa penitenciaria ni la institucionalidad cuentan con programas de acceso universal para la población penitenciaria. Esto, sumado a las precarias condiciones existentes al interior de los centros penitenciarios, hace poco verosímil la finalidad de reinserción social de la penal (Fregonara \& Ravera, 2018). Es una realidad que a todas luces no se evidencia en su pleno contexto, puesto que en la práctica no es garantizado a plenitud el acceso a la educación de los privados de la libertad y como consecuencia no se puede establecer, que se esté resocializando a los infractores de la ley penal, cuando no hay garantías de acceso a tal derecho fundamental. Es precisamente la resocialización la finalidad de la pena y del tratamiento penitenciario; pero, si todo el sistema padece una crisis estructural, grave y permanente, la resocialización será lo último a lograr. Y si para una sociedad tener delincuentes es un fracaso, doble fracaso será que estos transiten por las prisiones cual escuela de criminalidad. ¿Qué hacer entonces? Educar, al parecer de esta tesis, es el medio ideal para lograr exitosamente la resocialización y como consecuencia un medio para redimir o descontar a la vez, parte de la pena impuesta por un juez al condenado (García,C., 2015)

En la sociedad actual (Molano, 2011), existe una tendencia generalizada que intenta esconder aquellos grupos sociales que no han retenido la linealización de conductas que no se realizan según las normas, y reducirlas a espacios aislados. Por lo tanto, la tendencia de marginación, cierre y exclusión en las cárceles se designa como un espacio tangible diseñado para limitar a las personas y proteger a la sociedad de su daño. Sin embargo, en este tipo de comportamientos, la fragilidad de la memoria colectiva les hace enfrentar repetidamente la peor sentencia que pueden enfrentar: el olvido, esta es una forma de muerte. De hecho; por tanto, el interés por resolver el conocimiento de las condiciones de la población penitenciaria en materia educativa es particularmente importante, ya que desde que se realizó cualquier investigación, este interés no ha sido resuelto ni siquiera recibido la atención que merece. Desde todos los ángulos, todos los esfuerzos para liberar a los habitantes de la prisión de la "invisibilidad" y crecer, abrirse y establecer conexiones con la sociedad no solo son deseables sino también necesarios. Lo más importante, cuando es necesario superar las condiciones desiguales de este grupo social.

En relación con los derechos fundamentales de los reclusos (López, 2011), la legislación penitenciaria, con base en la Constitución española, tiene que articular un adecuado sistema prestacional de derechos fundamentales, debiendo llevarlo la Administración penitenciaria a efecto y crear un escenario en el que se interrelacione la ejecución de la pena privativa de libertad en prisión y el ejercicio de los derechos fundamentales que no se encuentren afectados por la condena. Por eso, no es tanto la cuestión que se debe abordar el que los presos tengan reconocidos derechos fundamentales cuanto la garantía y el reconocimiento de los mismos. La realidad que se vive en el sistema penitenciario peruano, que por su ineficacia crea condiciones "especiales" en la clandestinidad 
porque los planes y programas utilizados no son los mismos (Mamani \& Huamán, 2018), no hay suficientes operadores para formar el equipo multidisciplinario, agregando que debido al hacinamiento de los presos en las cárceles peruanas, la logística y el equipamiento disponible para realizar el trabajo es muy limitado. La reforma de la pena privativa de libertad, suspendida en su ejecución afecta o beneficia en la resocialización del sujeto penado al cual se le otorgó dicho beneficio y si verdaderamente influye de manera positiva este beneficio, en las sentencias condenatorias por delitos contra el patrimonio-robo agravado y agresión física en la sala Penal de Lima Norte 2017(Briceño, 2018).

Los factores de la realidad penitenciaria de servicio de salud, trabajo e infraestructura inciden de manera determinante en la vulneración de los derechos humanos de los internos del penal Challapalca; es así que los internos enuncian que la infraestructura del penal de Challapalca no es adecuado vulnerándose el derecho a un ambiente adecuado; en el factor de trabajo se vulnera al derecho de trabajo; en cuanto si se soslaya el derecho a la salud el $89,2 \%$ (58) internos del penal declaran que el servicio de salud penitenciaria es mala en la atención a los internos. (Chaiña, 2014)

Toda persona privada de la libertad goza de iguales derechos que cualquier otra, salvo los afectados por la ley y la sentencia (Artículo 63 CEP). La arquitectura penitenciaria en el Perú, los altos niveles de ingreso y el hacinamiento que actualmente es una problemática que influye en el proceso de resocialización de los internos, debido que muchos penales tienen un déficit en su infraestructura. El Penal San Antonio tiene como objetivo reubicar este equipamiento a un sector adecuado dando un enfoque sostenible para readaptación social de los reclusos, mediante el análisis de la situación actual del penal, además trabajos de investigación referenciales y el estudio de las necesidades de los usuarios directos e indirectos que influirá en el diseño y el emplazamiento del proyecto (Zamalloa, 2018).

Pena: "Castigo impuesto por la autoridad legítima especialmente de índole judicial a quien ha quien ha cometido un delito o falta" (Barba, 2000, pág. 134).

Reeducación: "La reeducación es el proceso por el cual una persona que tiene la condición de interno en un penal vuelve a estudiar, vuelve a aprender, vuelve a instruirse de aquello que alguna vez aprendió, que por diversas circunstancias desaprendió o perdió la capacidad para hacerlo, consiste en educar o enseñar nuevamente, este concepto se utiliza muy frecuentemente en la medicina y en el sistema penitenciario" (Arroyo M. , 2018, pág. 187).

Régimen penitenciario: "Conjuntos de normas legislativas o administrativas encaminadas a determinar los diferentes sistemas adoptados para que los penados cumplan sus penas. Se encamina a obtener la mayor eficacia en la custodia o en la readaptación social de los delincuentes". (Briceño, 2018, pág. 134).

Rehabilitación: "Cuando el autor de un delito ha sido condenado a pena que lleva aparejada la inhabilitación, absoluta o especial, puede ser rehabilitado; es decir, restituido al uso y goce de los derechos y capacidades de que fuera privado" (Briceño, 2018, pág. 134).

Reincorporación: "La reincorporación, Ilamada también reintegración o nueva adaptación, opera después de cumplir parte de su condena, siempre y cuando se haya sometido al tratamiento penitenciario y esta haya sido internalizado de manera positiva, inculca principios, valores, buenas prácticas, capacitación para el trabajo, etc." (De Miguel, 2014, pág. 155).

Resocialización: "Proceso de interacción y comunicación entre el individuo y la sociedad que no puede ser determinado unilateralmente ni por el individuo ni por la sociedad" (De Miguel, 2014, pág. 155).

\section{OBJETIVO}

Determinar en qué medida se garantiza el derecho a la educación en la resocialización de los internos en el establecimiento penitenciario Pocollay de Tacna, 2019. 


\section{METODOLOGÍA}

Método, hipotético-inductivo, partiendo de casos particulares para llegar a una proposición general. El proceso de Análisis y Síntesis, permite descomponer el objeto que estudia en sus elementos para luego recomponerlo a partir de la integración de estos, para así destacar el sistema de relaciones existentes entre las partes y el todo. (Villabella, 2015, pág. 921). La investigación es básica, no experimental de corte transversal, no se manipuló las variables, sino que los datos fueron recogidos después de ocurrido el hecho; y está referido al período 2019. (Hernández \& Fernández, 2014, pág. 534). El nivel de investigación es descriptivo, porque se especifica las características y rasgos importantes del fenómeno analizado; $y$, porque se explica por qué las dos variables están relacionadas (causa-efecto), el porqué de las cosas, hechos y fenómenos o situaciones. (Olvera, 2014, pág. 414).

Las variables que se midieron fueron: El derecho a la educación que comprende las siguientes dimensiones: Asequibilidad (Infraestructura, Recursos materiales didácticos y Oferta educativa), Accesibilidad (Inclusión en procesos educativos, Acceso a programas educativos y Gratuidad de enseñanza), Aceptabilidad (Contenidos actualizados, Programas de enseñanza acordes con las expectativas de los internos y Calidad de los programas educativos) y Adaptabilidad (Oferta educativa de acuerdo con los intereses y requerimientos de los internos, Tipos de programas educativos acorde con sus objetivos de resocialización y Programas educativos suficientes para satisfacer las diferentes necesidades de los internos). La segunda variable es la Resocialización de los internos cuyas dimensiones son: Reeducación (Técnicas de capacitación, Programas reeducadores y Tipos de programas en los diferentes niveles de instrucción), Rehabilitación (Actividades educativas rehabilitadoras y Programas educativos rehabilitadores), Reincorporación (Corrección de conducta, Capacitación y Preparación para ocupar puesto de trabajo). Donde la medida se da por el Nivel de resocialización (Alto, Medio y Bajo).

Las unidades de estudio comprenden a 114 internos matriculados en un programa educativo en el Centro Penitenciario. Para la determinación de la muestra se aplicó el muestreo probabilístico, aleatorio, resultando un tamaño final de 88 internos matriculados en un programa educativo

Como técnicas para el desarrollo de la investigación se utilizó la encuesta, la entrevista y el análisis documental. Los instrumentos de medición que se aplicaron fueron: Cuestionario, la cédula de entrevista y la ficha de análisis documental. El instrumento de medición del cuestionario fue sometido a la prueba de validez y confiabilidad. La prueba de validez se hizo a través del juicio de expertos, realizado por doctores en derecho y conocedores de metodología de la investigación. Asimismo, la prueba de confiabilidad se realizó a través del Coeficiente del Alfa de Cronbach, cuyo índice alcanzó el 0,81 , el cual demuestra la confiabilidad del instrumento aplicado.

\section{RESULTADOS}

El 45,4\% de los internos manifiestan que "definitivamente no" se garantiza la asequibilidad del derecho a la educación en la resocialización de los internos. El 40,9\% que "definitivamente no" se garantiza la accesibilidad del derecho a la educación en la resocialización, el $40 \%$ de los internos manifiestan que "definitivamente no" se garantiza la aceptabilidad del derecho a la educación en la resocialización de los internos, el $44,3 \%$ de los internos manifiestan que "definitivamente no" se garantiza adaptabilidad del derecho a la educación en la resocialización de los internos.

Tabla 1

Resultados del Derecho a la educación

\begin{tabular}{|c|c|c|}
\hline Dimensiones & Respuesta & Promedio \\
\hline Asequibilidad & Definitivamente no & 45.4 \\
\hline Accesibilidad & Definitivamente no & 40.9 \\
\hline Aceptabilidad & Probablemente no & 41.3 \\
\hline Adaptabilidad & Definitivamente no & 44.3 \\
\hline & Promedio & 43.0 \\
\hline
\end{tabular}


Tabla 2

El derecho a la educación

\begin{tabular}{|c|c|c|c|c|c|c|c|c|c|c|}
\hline \multirow[t]{2}{*}{ Valoración } & \multicolumn{2}{|c|}{$\begin{array}{l}\text { Definitiva- } \\
\text { mente no }\end{array}$} & \multicolumn{2}{|c|}{$\begin{array}{l}\text { Probable- } \\
\text { mente no }\end{array}$} & \multicolumn{2}{|c|}{ Indeciso } & \multicolumn{2}{|c|}{$\begin{array}{l}\text { Probable- } \\
\text { mente si }\end{array}$} & \multicolumn{2}{|c|}{$\begin{array}{l}\text { Definitiva- } \\
\text { mente si }\end{array}$} \\
\hline & $\mathrm{Fi}$ & $\%$ & $\mathrm{Fi}$ & $\%$ & $\mathrm{Fi}$ & $\%$ & $\mathrm{Fi}$ & $\%$ & $\mathrm{Fi}$ & $\%$ \\
\hline \multicolumn{11}{|c|}{ Asequibilidad } \\
\hline $\begin{array}{l}\text { ¿Se cuenta con los ambientes educativos y } \\
\text { materiales didácticos para garantizar su } \\
\text { educación? }\end{array}$ & 42 & 47.7 & 33 & 37.5 & 1 & 1.1 & 11 & 12.5 & 1 & 1.1 \\
\hline $\begin{array}{l}\text { ¿Se cuenta con docentes calificados para } \\
\text { garantizar su educación penitenciaria? }\end{array}$ & 44 & 50 & 29 & 33 & 1 & 1.1 & 14 & 15.9 & 0 & 0 \\
\hline $\begin{array}{l}\text { ¿Considera Ud., que se cuenta con programas } \\
\text { educativos variados? }\end{array}$ & 34 & 38.6 & 36 & 40.9 & 6 & 6.8 & 11 & 12.5 & 1 & 1.1 \\
\hline Porcentaje promedio & 40.0 & 45.4 & 32.7 & 37.1 & 2.7 & 3.0 & 12.0 & 13.6 & 0.7 & 0.7 \\
\hline \multicolumn{11}{|c|}{ Accesibilidad } \\
\hline $\begin{array}{l}\text { ¿Considera Ud., que tiene la posibilidad de } \\
\text { participar en procesos educativos sin ser } \\
\text { discriminado o excluido? }\end{array}$ & 27.0 & 30.7 & 42.0 & 47.7 & 1.0 & 1.1 & 17.0 & 19.3 & 0.0 & 0.0 \\
\hline $\begin{array}{l}\text { ¿Considera Ud., que se cuenta con los } \\
\text { programas educativos suficientes para su } \\
\text { resocialización? }\end{array}$ & 54.0 & 61.4 & 29.0 & 33.0 & 4.0 & 4.5 & 1.0 & 1.1 & 0.0 & 0.0 \\
\hline $\begin{array}{l}\text { ¿Los programas de educación que le ofrece el } \\
\text { INPE, son gratuitos? }\end{array}$ & 27.0 & 30.7 & 6.0 & 6.8 & 4.0 & 4.5 & 49.0 & 55.7 & 2.0 & 2.3 \\
\hline Porcentaje promedio & 36.0 & 40.9 & 25.7 & 29.2 & 3.0 & 3.4 & 22.3 & 25.4 & 0.7 & 0.8 \\
\hline \multicolumn{11}{|c|}{ Aceptabilidad } \\
\hline $\begin{array}{l}\text { ¿Considera Ud., que en los programas } \\
\text { educativos se imparten contenidos acordes a } \\
\text { la realidad del país? }\end{array}$ & 29.0 & 33.7 & 33.0 & 37.5 & 15.0 & 17.0 & 9.0 & 9.1 & 3.0 & 3.4 \\
\hline $\begin{array}{l}\text { ¿Considera Ud., que los programas } \\
\text { educativos son variados y de acuerdo a sus } \\
\text { expectativas? }\end{array}$ & 31.0 & 35.2 & 42.0 & 47.7 & 6.0 & 6.8 & 6.0 & 6.8 & 3.0 & 3.4 \\
\hline $\begin{array}{l}\text { ¿Considera que los programas educativos } \\
\text { ofertados son de calidad? }\end{array}$ & 45 & 51.1 & 34 & 38.6 & 8 & 9.1 & 1 & 1.1 & 0 & 0.0 \\
\hline Porcentaje promedio & 35.0 & 40.0 & 36.3 & 41.3 & 9.7 & 11.0 & 5.3 & 5.7 & 2.0 & 2.3 \\
\hline \multicolumn{11}{|c|}{ Adaptabilidad } \\
\hline $\begin{array}{l}\text { ¿Considera Ud., que la oferta educativa está } \\
\text { de acuerdo con los intereses y } \\
\text { requerimientos de los internos? }\end{array}$ & 35 & 39.8 & 43 & 48.9 & 5.0 & 5.7 & 2.0 & 2.3 & 3 & 3.4 \\
\hline $\begin{array}{l}\text { ¿Considera que se cuenta con tipos de } \\
\text { programas educativos acorde con sus } \\
\text { objetivos de resocialización? }\end{array}$ & 36.0 & 40.9 & 41.0 & 46.6 & 10 & 11.4 & 1 & 1.1 & 0.0 & 0.0 \\
\hline $\begin{array}{l}\text { ¿Considera que se cuenta con programas } \\
\text { educativos suficientes para satisfacer las } \\
\text { diferentes necesidades de los internos? }\end{array}$ & 46 & 52.3 & 32 & 36.4 & 10 & 11.4 & 0.0 & 0.0 & 0.0 & 0.0 \\
\hline
\end{tabular}

En la tabla 2, el promedio de las puntuaciones alcanzadas sobre el derecho a la educación es de $43 \%$, para la alternativa de "definitivamente no" lo que nos permite determinar que el derecho a la educación se garantiza en mínima medida en la resocialización de los internos en el establecimiento penitenciario Pocollay de Tacna, 2019.

\section{Tabla 3}

Resultados de la resocialización

\begin{tabular}{|c|c|c|}
\hline Dimensiones & Respuesta & Promedio \\
\hline Reeducación & Definitivamente no & 53.0 \\
\hline Rehabilitación & Definitivamente no & 44.7 \\
\hline Reincorporación & Definitivamente no & 51.9 \\
\hline \multirow[t]{2}{*}{ Nivel de resocialización } & Definitivamente no & 54.9 \\
\hline & Promedio & 51.1 \\
\hline
\end{tabular}


El promedio de las puntuaciones alcanzadas sobre la resocialización de los internos es de $51,1 \%$, para la alternativa de "definitivamente no", lo que nos permite determinar que no se garantiza la resocialización de los internos en el establecimiento penitenciario Pocollay de Tacna, 2019.

El 53\% de los internos manifiestan que "definitivamente no" se garantiza la reeducación en la resocialización de los internos, el $44,7 \%$ de los internos manifiestan que "definitivamente no" se garantiza la rehabilitación en la resocialización, el $51,9 \%$ de los internos manifiestan que "definitivamente no" se garantiza la reincorporación en la resocialización de los internos, el 54,9\% de los internos manifiestan que el nivel de resocialización de los internos en el establecimiento penitenciario Pocollay de Tacna, 2019, es bajo. (Tabla 3)

Tabla 4

Resocialización de los internos

\begin{tabular}{|c|c|c|c|c|c|c|c|c|c|c|}
\hline \multirow[t]{2}{*}{ Valoración } & \multicolumn{2}{|c|}{$\begin{array}{l}\text { Definitivamen } \\
\text { te no }\end{array}$} & \multicolumn{2}{|c|}{$\begin{array}{l}\text { Probablemen } \\
\text { te no }\end{array}$} & \multicolumn{2}{|c|}{ Indeciso } & \multicolumn{2}{|c|}{$\begin{array}{l}\text { Probablemen } \\
\text { te si }\end{array}$} & \multicolumn{2}{|c|}{$\begin{array}{l}\text { Definitivam } \\
\text { ente si }\end{array}$} \\
\hline & $\mathrm{Fi}$ & $\%$ & $\mathrm{Fi}$ & $\%$ & $\mathrm{Fi}$ & $\%$ & $\mathrm{Fi}$ & $\%$ & $\mathrm{Fi}$ & $\%$ \\
\hline \multicolumn{11}{|c|}{ Reeducación } \\
\hline $\begin{array}{l}\text { ¿El área de educación penitenciaria emplea adecuadas } \\
\text { técnicas para que el interno pueda capacitarse para } \\
\text { insertarse en la sociedad? }\end{array}$ & 49 & 55.7 & 37 & 42,0 & 0.0 & 0.0 & 1.0 & 1.1 & 1.0 & 1.1 \\
\hline $\begin{array}{l}\text { ¿El sistema penitenciario, reeduca a través de los } \\
\text { programas de alfabetización, educación primaria y } \\
\text { secundaria para adultos y educación técnico productivo } \\
\text { para el trabajo? }\end{array}$ & 45.0 & 51.1 & 33.0 & 37.5 & 4 & 4.5 & 4 & 4.5 & 2.0 & 2.3 \\
\hline $\begin{array}{l}\text { ¿El centro penitenciario, cuenta con adecuados } \\
\text { programas para que el interno pueda volver a estudiar, } \\
\text { aprender e instruirse para resocializarse? }\end{array}$ & 46 & 52.3 & 34 & 38.6 & 0 & 0.0 & 8.0 & 9.1 & 0.0 & 0.0 \\
\hline
\end{tabular}

\begin{tabular}{|c|c|c|c|c|c|c|c|c|c|c|}
\hline Porcentaje promedio & 46.7 & 53.0 & 34.7 & 38.1 & 1.3 & 1.5 & 4.3 & 4.9 & 1.0 & 1.1 \\
\hline \multicolumn{11}{|c|}{ Rehabilitación } \\
\hline $\begin{array}{l}\text { ¿Las actividades educativas rehabilitadoras le permitirán } \\
\text { su rehabilitación social? }\end{array}$ & 35 & 39.8 & 37 & 42.0 & 5.0 & 5.7 & 9.0 & 10.2 & 2.0 & 2.3 \\
\hline $\begin{array}{l}\text { ¿Las actividades educativas le permitieron cambiar su } \\
\text { personalidad dañada, generando expectativas para su } \\
\text { desarrollo personal? }\end{array}$ & 37.0 & 42.0 & 38.0 & 43.2 & 0 & 0.0 & 13 & 14.8 & 0.0 & 0.0 \\
\hline $\begin{array}{l}\text { ¿Los programas educativos le han permitido cambiar su } \\
\text { conducta rehabilitándola para insertarse en la sociedad? }\end{array}$ & 46 & 52.3 & 34 & 38.6 & 0 & 0.0 & 8.0 & 9.1 & 0.0 & 0.0 \\
\hline Porcentaje promedio & 39.3 & 44.7 & 36.3 & 41.3 & 1.7 & 1.9 & 10.0 & 11.4 & 0.7 & 0.8 \\
\hline \multicolumn{11}{|c|}{ Reincorporación } \\
\hline $\begin{array}{l}\text { ¿Considera Ud. que el tratamiento educativo } \\
\text { penitenciario es una buena herramienta para } \\
\text { reincorporarse a la sociedad de manera positiva? }\end{array}$ & 35 & 39.8 & 36 & 40.9 & 0.0 & 0.0 & 15.0 & 17.0 & 2.0 & 2.3 \\
\hline $\begin{array}{l}\text { ¿Considera Ud. que los tipos de programas educativos } \\
\text { impartidos le han permitido estar capacitado para hacer } \\
\text { frente a los retos que la sociedad demanda? }\end{array}$ & 44.0 & 50.0 & 36.0 & 40.9 & 4 & 4.5 & 2 & 2.3 & 2 & 2.3 \\
\hline $\begin{array}{l}\text { ¿Considera Ud. que se ha preparado para incorporarse a } \\
\text { un puesto de trabajo de manera positiva? }\end{array}$ & 58 & 65.9 & 26 & 29.5 & 0 & 0.0 & 4.0 & 4.5 & 0.0 & 0.0 \\
\hline Porcentaje promedio & 45.7 & 51.9 & 32.7 & 37.1 & 1.3 & 1.5 & 7.0 & 7.9 & 1.3 & 1.5 \\
\hline \multicolumn{11}{|c|}{ Nivel de Resocialización } \\
\hline $\begin{array}{l}\text { ¿Considera usted que se encuentra reeducado para } \\
\text { incorporarse a la sociedad? }\end{array}$ & 47 & 53.4 & 33.0 & 37.5 & 0 & 0.0 & 6.0 & 6.8 & 2.0 & 2.3 \\
\hline $\begin{array}{l}\text { ¿Considera usted que se encuentra rehabilitado para } \\
\text { incorporarse a la sociedad? }\end{array}$ & 46 & 52.3 & 32.0 & 36.4 & 0 & 0.0 & 7 & 7.8 & 3 & 3.4 \\
\hline $\begin{array}{l}\text { ¿Considera usted que la educación penitenciaria } \\
\text { impartida le permitirá reincorporarse a la sociedad } \\
\text { satisfactoriamente? }\end{array}$ & 52 & 59.1 & 29 & 33.0 & 0 & 0.0 & 7.0 & 8.0 & 0.0 & 0.0 \\
\hline Porcentaje promedio & 48.3 & 54.9 & 31.3 & 35.6 & 0.0 & 0.0 & 6.7 & 7.5 & 1.7 & 1.9 \\
\hline
\end{tabular}

Por lo que se puede determinar el bajo número de internos matriculados en algún tipo de servicio educativo, y la ausencia de participación en los diferentes tipos de servicios educativos. Se puede concluir que la mayoría de los internos han preferido la educación técnico-productiva, capacitándose en cuero y calzado y mecánica y motores. 
Tabla 5

Tipo de educación técnico productiva

\begin{tabular}{lcc}
\hline Tipo de Educación Técnico productiva & Total de matriculados & $\%$ \\
\hline Construcciones I & 28 & 24.6 \\
Cuero y calzado I & 29 & 25.4 \\
Mecánica y motores I & 29 & 25.4 \\
Textil y confecciones I & 28 & 24.6 \\
Total & 114 & 100 \\
\hline
\end{tabular}

\section{Correlación de Pearson}

\begin{tabular}{llrr}
\hline & & Derecho a la educación & Resocialización \\
\hline Derecho a la & Correlación de Pearson & 1 & $0.730\left(^{* *}\right)$ \\
educación & Sig. (bilateral) & & 0.000 \\
& $\mathrm{~N}$ & 88 & 88 \\
\hline Resocialización & Correlación de Pearson & $0.730\left(^{* *}\right)$ & 1 \\
& Sig. (bilateral) & 0.000 & 88 \\
& $\mathrm{~N}$ & 88 & 8 \\
\hline
\end{tabular}

**La correlación es significativa al nivel 0,01 (bilateral).

En conclusión, desde la perspectiva del personal en reclusión, esto significa que existe una correlación directa entre los índices del derecho a la educación y resocialización (Correlación de Pearson: 0.7). Es decir que existe un $73 \%$ de probabilidad que el derecho a la educación; tenga una relación directa en la resocialización de los internos del penal. En la realidad, el derecho a la educación se garantiza en mínima medida en la resocialización de los internos en el establecimiento penitenciario Pocollay de Tacna, 2019.

\section{DISCUSIÓN}

La presente investigación tuvo como objetivo analizar en qué medida se garantiza el derecho a la educación en la resocialización de los internos en el establecimiento penitenciario Pocollay de Tacna, 2019. El derecho a la educación se garantiza en mínima medida en la resocialización de los internos en el establecimiento penitenciario Pocollay de Tacna, 2019. Estos resultados guardan relación con el estudio de (Fregonara \& Ravera, 2018), "el derecho de los condenados a acceder a una educación al interior de los Centros Penitenciarios resulta en extremo difícil cuando ni la normativa penitenciaria ni la institucionalidad cuentan con programas de acceso universal para la población penitenciaria. Esto, sumado a las precarias condiciones existentes al interior de los centros penitenciarios, hace poco verosímil la finalidad de reinserción social de la penal".

Asimismo, los resultados del presente estudio también guardan relación con el estudio de: (García,C., 2015), el cual señala que, "en la práctica no es garantizado a plenitud el acceso a la educación de los privados de la libertad y como consecuencia no se puede establecer, que se esté resocializando a los infractores de la ley penal, cuando no hay garantías de acceso a tal derecho fundamental". Adicionalmente, (Molano, 2011), quien señala que: "la tendencia a marginar, encerrar y excluir se concreta en la cárcel como espacio físico construido con la intencionalidad de recluir personas, de resguardar o proteger a la sociedad de la peligrosidad de los mismos. La fragilidad del recuerdo colectivo los lleva en muy repetidas ocasiones a la peor condena que pueden afrontar: el olvido; que es una forma de morir. Por esto resulta especialmente significativo el interés de abordar el conocimiento de la situación de la población carcelaria en relación con el tema de la educación, el cual no ha sido abordado desde ninguna investigación y ni siquiera documentado con la profundidad que amerita su importancia. Todo esfuerzo realizado para sacar de la "invisibilidad" a los habitantes de la prisión, para generar propuestas de crecimiento, apertura y articulación a la sociedad son, desde todo punto de vista, no solo deseables sino necesarios. Ante todo, cuando se trata de una apertura para superar las condiciones de inequidad de este grupo social". Finalmente (Arroyo M. , 2018), señala que, "las conclusiones de los resultados estadísticos contrastados, dan cuenta la existencia de una relación 
$r=0.0408$ entre las variables educación penitenciaria y resocialización y tienen un nivel de correlación positiva media, cuya significancia es $p=0,003$, muestra menor al 0,05; donde además hemos encontrado que en los niveles de descripción, la percepción que tiene los liberados para la primera variable es del $64 \%$ percibida como mala, el $30 \%$ como regular y solo el $6 \%$ es considerada buena; respecto a la segunda variable que el $12 \%$ es considerada como mala, el $16 \%$ como regular y el $72 \%$ es percibida como buena".

\section{CONCLUSIONES}

El derecho a la educación es un derecho fundamental intrínseco y, a la vez, un medio indispensable para la plena realización de otros derechos fundamentales, por cuanto permite al ciudadano participar plenamente en la vida social y política en su comunidad, siendo que este derecho no solo se constituye como un derecho fundamental, sino que se trata además de un servicio público, debiéndose por parte del Estado garantizarse que esta impartición educativa sea digna. El derecho a la educación se garantiza en mínima medida en la resocialización de los internos en el establecimiento penitenciario Pocollay de Tacna, 2019. El coeficiente de relación del 0, 73\% señala que existe la probabilidad que el derecho a la educación tiene una relación directa en la resocialización, al hallarse que la asequibilidad, accesibilidad, aceptabilidad; $y$ adaptabilidad del derecho a la educación se garantiza en mínima medida lo que no permite una adecuada resocialización de los internos en el establecimiento penitenciario Pocollay de Tacna. La educación al interior del Establecimiento Penitenciario de Varones de Pocollay, tiene limitaciones en su impartición en cuanto a el Sistema educativo no garantizándose las características interrelacionadas y fundamentales de disponibilidad, accesibilidad, aceptabilidad, adaptabilidad, las mismas que según la contratación de las hipótesis del presente trabajo de investigación repercute en el bajo nivel de resocialización de los internos sentenciados.

\section{PROPUESTA LEGISLATIVA}

PROYECTO DE LEY

Proyecto de Ley que declara de necesidad pública y de interés nacional establecer la educación como medio obligatorio para la resocialización de los internos en los Centros Penitenciarios

\section{ARTícULO 1․- Objeto de la Ley.}

El Proyecto de Ley tiene como objeto declarar de necesidad pública y de interés nacional establecer la educación a través de sus diferentes modalidades como "medio obligatorio para la resocialización de los internos en los Centros Penitenciarios del país".

\section{Artículo 2.- Entidad encargada}

Encargase al Ministerio de Justicia y Derechos Humanos, al Ministerio de Educación, al Instituto Nacional Penitenciario (INPE) con cargo a sus presupuestos, de conformidad con sus competencias, atribuciones impulsar progresivamente y de acuerdo a la capacidad presupuestal, la educación penitenciaria a través de la enseñanza básica, media, técnica, profesional y superior, articulando el proceso educativo con la cooperación de la familia, la comunidad, la empresa y la sociedad en general., en cumplimiento de lo dispuesto en el artículo 1 o de la presente Ley.

\section{ARTíCULO 2.- Reglamento.}

Para el cumplimiento de la presente ley, reglaméntese la misma en el plazo 60 días.

\section{ARTícULO 3.- Vigencia.}

La presente ley entrada en vigencia con la expedición de su reglamento.

\section{EXPOSICIÓN DE MOTIVOS}

- Existe una mínima garantía del derecho a la educación en la resocialización de los internos en el establecimiento penitenciario.

- La asequibilidad, accesibilidad, aceptabilidad, adaptabilidad del derecho a la educación se garantiza en mínima medida en la resocialización de los internos en los establecimientos penitenciarios. 
- La garantía del derecho a la educación tiene un mínimo efecto en la reeducación de los internos.

- La garantía del derecho a la educación tiene un mínimo efecto en la rehabilitación de los internos

- La garantía del derecho a la educación tiene un mínimo efecto en la reincorporación de los internos en los establecimientos penitenciarios.

\section{ANÁLISIS COSTO BENEFICIO}

La presente iniciativa no irrogará gastos al Estado, por el contrario, permitirá asegurar la resocialización de los interno; y de esta manera garantizar su integración y desarrollo en la sociedad; ; la presente propuesta legislativa permitirá ofrecer a los estudiantes desfavorecidos una segunda oportunidad de aprender, encontrar formas de reconocer y validar el conocimiento, aprovechar el uso de las nuevas tecnologías y ampliar sus oportunidades, actúa en beneficio de todos, es decir, no es solamente un proceso unidireccional de reducción de la reincidencia. Las estadísticas afirman que los bajos niveles de cualificación tienen importantes efectos negativos en la empleabilidad de los presos una vez liberados y es una de las principales razones por las que los expresos reinciden.

La aprobación de la modificación planteada no amerita ningún gasto al Tesoro Público, porque se trata de implementar una norma legal en el Código Penal, a fin de beneficiar a los internos y garantizar su integración a la sociedad peruana.

\section{EFECTOS EN LA LEGISLACIÓN}

La presente propuesta tiene como finalidad establecer la educación en los establecimientos penitenciarios, a fin de propiciar la reeducación, rehabilitación y reincorporación de los internos y garantizar una eficiente resocialización de los internos para su integración y desarrollo en la sociedad peruana.

\section{REFERENCIAS}

Arroyo, M. (2018). Educación penitenciaria y resocialización de internos liberados del establecimiento penitenciario de Huaral 2014 y 2015 . Chimbote: Universidad César Vallejo.

Barba, B. (2000). Educación para los derechos humanos, Los derechos humanos como educación valoral. Mexico D.F.: ISBN.

Bolivia. Ministerio de Gobierno. (19 de 01 de 2017). Situación de las Cárceles en Bolivia. Bolivia. La Paz.

Briceño, A. (2018). Reforma de una pena efectiva por una suspendida y el proceso de resocialización del reo -2da sala penal Lima Norte, 2017. Lima: Universidad César Vallejo.

Caride, R., \& Pernas, L. (2012). Educación en instituciones penitenciarias del Ministerio de educación, cultura y deportes. Revista de educación en instituciones penitenciarias, 50-69.

Chaiña, H. (2014). Realidad penitenciaria y derechos humanos de los internos del penal de Challapalca, Tacna 2011. Puno: Unversidad Nacional del Altiplano.

Código de Ejecución Penal Peruano. (1991). Código de ejecución penal peruano. Lima: Gaceta jurídica.

De Miguel, M. (2014). Reinsecricón social y laboral del reo. España: Universidad de Valladolid.

ECURED. (19 de 01 de 2017). ecured.cu. Obtenido de ecured.cu: https://www.ecured.cu/Sistema_Penitenciario_Cubano

Fregonara, D., \& Ravera, C. (2018). Sistema penintenciario y derecho a la educación. Santiago: Universidad de Chile.

García, R. (2015). La Educación como derecho fundamental al interior de la prisión. Bogotá: Universidad Milltar de Nueva Granada. 
García,C. (2015). La educación como derecho fundamental al interior de la prisión. Bogotá: Universidad Militar Nueva Granada.

Gobierno de la República de Honduras. (12 de Marzo de 2015). tsc.gob.hn/leyes. Obtenido de tsc.gob.hn/leyes: http://www. tsc.gob.hn/leyes/REGLAMENTO_DE_LEY_ SISTEMA_PENITENCIARIO.pdf

Gobierno de la República de Guatemala. (20 de 01 de 2017). dgsp.gob.gt. Obtenido de dgsp.gob.gt: http://dgsp.gob.gt/wp-content/ uploads/2016/06/Reglamento.pdf

Hernández, R., \& Fernández, C. \&. (2014). Metodología de la investigación. México: Mc. Graw Hill.

López, M. (2011). Los derechos fundamentales de los presos y su reinserción social. Madrid: Universidad de Alcalá.

Mamani, B., \& Huamán, L. (2018). Sistema Penitenciario y Resocialización de Internos según sexo en el Establecimiento Penal San Francisco de Asís - Puerto Maldonado 2017- 2018. Puerto Maldonado: Universidad Nacional Amazónica de Madre de Dios.

Molano, E. (2011). Bogotá: Universidad Libre.

Morales, M. (2012). Proceso Educativo para la readaptación del recluso. Lima: Idemsa.

Nicaragua. Ministerio de Gobernación de Nicaragua. (5 de Agosto de 2014). migob.gob.ni. Obtenido de migob.gob.ni: http://www.migob.gob.ni/spn/programas/

Noriega, M. (20 de Marzo de 2016). Funciónjudicial.gob.pe. Obtenido de funcionjudicial.gob.pe: http://www.funcionjudicial.gob.ec/www/ pdf/concursojuecesnotarios/materialdeapoyo/ SISTEMA\%20\%20PENITENCIARIO\%20 EN\%20EL\%20ECUADOR\%20Dr.\%20 Marco\%20Noriega.pdf 7

Núñez, V. (2010). La educación que está llamada a articular el orden de lo particular de cada sujeto con el orden de lo social, aquello que es patrimonio común. Lima: Idemsa.

Olvera, J. (2014). Metodología de la investigación jurídica. México: Universidad Autónoma del Estado de México.

Paraguay. Ministerio de Justicia de la República del Paraguay. (19 de Enero de 2017). www.ministeriodejusticia.gov.py. Obtenido de www.ministeriodejusticia.gov.py: http://www.ministeriodejusticia.gov.py/index. php/centro-de-estudios-penitenciarios.

Scarfó, F. (19 de 01 de 2007). tumbi.crefal.edu.mx/. Obtenido de tumbi.crefal.edu.mx/: http://tumbi.crefal.edu.mx/decisio/images/pdf/decisio_16/decisio16_saber5.pdf

Scarfó, S., \& Castro, L. (2006). Estado, Educación y Cárceles. Lima: Gaceta Jurídica.

Sistema Carcelario y Libertad Condicional en Chile. (13 de Mayo de 2016). lyd.org/wp-content. Obtenido de lyd.org/ wp-content: http://lyd.org/ wp-content/uploads/2016/05/TP1254SISTEMA-CARCELARIO-Y-LIBERTADCONDICIONAL-EN-CHILE-13-05-2016.pdf

Venezuela.Gobierno Bolivariano de Venezuela. (17 de 01 de 2017). mppsp.gob.ve. Obtenido de mppsp.gob.ve: http://www.mppsp.gob.ve/libraries/organigrama_general.pdf

Villabella, C. (2015). Los métodos en la investigación jurídica. México: UNAM.

Zamalloa, K. (2018). Proyecto Arquitectónico sostenible del establecimiento penitenciario San antonio para la reinserción social de los internos en la región de Tacna. Tacna: Universidad Nacional Jorge Basadre Grohmann-Tacna. 